\title{
Research on the Present Development Situation and Countermeasures of Equestrian Tourism in China*
}

\author{
Donghua Zhou \\ Wuhan Business University \\ Wuhan, China
}

\author{
Yakun Huang \\ Wuhan Business University \\ Wuhan, China
}

\begin{abstract}
By using the methods of literature searching, expert consultation, market investigation and logical analysis, the concept of equestrian tourism has been defined, according to the developing status of equestrian tourism, equestrian tourism problems have been analyzed, and some countermeasures for the further development of equestrian tourism industry have been put forward, including the aspects of culture dissemination; the government's effective guidance, encouraging the development of characteristics of equestrian tourism town; improving the legislative system, the establishment of market regulation system; accelerating personnel training; expecting to provide theoretical reference for the future healthy development of equestrian tourism industry of China.
\end{abstract}

Keywords-equestrian tourism; current situation; development strategy

\section{INTRODUCTION}

As the global economy entered a new stage of development, the overall number of new rich rise sharply, large equestrian events of Olympic Games and National Games events, Chinese equestrian sports are thorough popular gradually; At the same time, China's equestrian population has increased rapidly, and a large number of foreign horses have entered China, and the number of domestic equestrian clubs has steadily increased. When the equestrian industry rapidly develop, domestic tourism is also booming, as the tourist population increase, the economic benefits of tourism are playing a great role on the national economic growth. Horse-related tourism activities are widely carried out throughout the country. In this context, the concept of equestrian tourism has emerged.

At present, equestrian tourism has not yet formed a specific theoretical and conceptual definition in terms of academics. Equestrianism and tourism are social and cultural activities and have rich cultural connotations. Equestrian tourism is a category of cultural tourism and it is an important part of sports tourism. After consulting materials and carrying out relevant investigations, we have drawn a preliminary concept of equestrian tourism, which refers to the activities of people in their leisure time aimed at

*Project support: 2017 Hubei educational department humanities and social science project (The research on the cooperative mode of the horse racing industry talents between Hubei and Xinjiang in the background of "One Belt And One Road"), Project No: 17G073. achieving physical fitness and pleasing body and mind by means of tourism combined with the theme of horses [1].

Equestrian tourism includes equestrian riding, outdoor recreational riding, Western equestrian, polo, horseback riding, equestrian culture festival and all kinds equestrian entertaining games. The equestrian tourism meets the aspiration of people to travel, and in this way, the sports equestrian program is integrate stimulation into the equestrian program, with the features of participatory, stimulation, entertainment, culture and spontaneity [2]. Equestrian tourism not only can meet the demands of people who want to gain knowledge and to develop business tourism, but also can satisfy the need of its enjoyable fitness, and gradually become a new fashion of sports consumer and the public.

\section{THE DEVELOPMENT SITUATION OF EQUESTRIAN}

\section{A. The Prospect of Equestrian Tourism is Promising}

1) The overall market for tourism is booming: With the rapid development of society, tourism is gradually becoming one of the most powerful and largest industries in the global economy. In the economic development of the city, tourism plays an important role; the industrial status and economic role of the tourism industry are gradually increasing, and playing an important role in the development of the urban economy, the labor force, and the development of culture and environment, tourism industry has become one of the pillar industries in China's economic development.

The annual tourism statistics report of 2016 shows that the tourism economy in 2016 has achieved rapid growth, the number of domestic tourists totaled 4.44 billion, up $11.0 \%$ from the same period last year. Domestic tourism revenue was 3.94 trillion yuan, up 15.19 percent year on year. China's sports tourism scale will reach 1 trillion yuan in the future, while the current figure is 170 billion yuan, according to a report by CITIC construction investment securities [3]. As one of the most demanding tourist products in the world, the demand of tourist in China is still growing, and there is a huge market behind it. The two new formats of equestrianism and tourism are bound to enter the fast lane of development when the domestic tourism environment is great.There is huge potential economic value for equestrian 
leisure tourism, which is a vast market and has great prospects for development.

2) Relevant policy guidance: In the "Opinions on Accelerating the Development of the Sports Industry and Promoting the Consumption of Sports" officially issued by the State Council[4], China regard s "Equestrianism" as one of the key developing projects that the country strongly supports . In addition, the national tourism administration proposes to standardize the development strategy of tourism market, encouraging social capital to participate in tourism development, to promote investment and development of tourism industry.

The national policy strongly supports the development of leisure sports, and the development of the equestrian tourism market will be more favorable on the basis of the development of leisure tourism in various preferential policies. As a new form of leisure tourism, equestrian tourism has a very broad consumer market with a certain horse culture in China.

\section{B. The State of Rapid Development of Equestrian Tourism}

The equestrian tourism in China has developed rapidly, and all kinds of equestrian sports have developed well. The equestrian movement, such as show jumping, dressage, Western equestrian, and other related associations, club members and large equestrian events has increased dramatically. According to the statistics of the China Equestrian Association,, the number of domestic equestrian clubs has reached more than 1000 in 2017. At the same time, the equestrian clubs in the second and third-tier cities in China are developing rapidly. Each year, 20 to 30 clubs will be added. The number of imported horses in the country has exceeded 2,300, and these horses have imported nearly RMB 500 million [5]. In addition, according to Equestrian magazine statistics, in 2016, the number of national-level and above events has reached 46 games. The total number of international, national, provincial and municipal competitions has exceeded 200 games. Overall speaking, the development of the entire equestrian tourism is in a good situation.

\section{PROBLEMS IN THE DEVELOPMENT OF EQUESTRIAN TOURISM IN CHINA}

\section{A. Weak Awareness of Cultural Development}

The development of horse culture is a necessary factor for the development of equestrian tourism. The development of equestrian tourism cannot be separated from the horse culture. China has a long and splendid horse culture, and its cultural connotation is rich and varied [6]; However, with the poor awareness of the development and protection of horse culture in the new century, the "fault" of the development of horse culture has caused more and more people to have a strange sense of horse culture and greatly diminish the love of horses, which greatly hinders the development of equestrian tourism.

\section{B. Lacking of Effective Government Guidance}

1) Lack of effective coordination mechanisms: Equestrian tourism is a comprehensive industry, which combines of equestrian and tourism, involving a wide range. The healthy and orderly development of equestrian tourism requires the establishment of a well-organized, harmonious and multi-participatory coordination management mechanism among various government departments. Coordination mechanism is not sound among various departments, which not only cannot get effective integration, efficient utilization of resources, but also hinders the equestrian tourism enterprises enthusiasm of the micro level, and influences of the rapid development of the tourism industry. For example, when launching the bidding of Tourism Culture Festival and characteristic horse racing festival, there will be multiple departments, associations and various management to make management confusion. We must establish a synergy mechanism among the relevant government departments to solve this problem.

2) Lacking of professional system planning: Equestrian tourism planning has a leading role in the development of equestrian tourism. At present, China has formulated the "Several Opinions of the State Council on Accelerating the Development of Sports Industry and Promoting Sports Consumption" (GF (2014) No. 46), which for the first time pointed out to develop equestrian sports. In the fourth part of the "13th Five-Year Plan for Sports Development," "IV. Implementation of the National Fitness National Strategy, Accelerate the Promotion of Mass Sports Development,"[7] the document explicitly states that it is necessary to cultivate equestrian and other fashion sports. However, so far our country has not issued a special plan for the development of equestrian tourism. Equestrian tourism lacks given systematic planning and guidance in the development of equestrian tourism. There are problems in the domestic equestrian tourism development projects such as unclear location, rough design, unreasonable layout, and low awareness of sustainable development and so on. The development of equestrian tourism must be on the right track, and it is inseparable from the professional planning of the system.

3) Relevant laws and regulations are not perfect, market norms are inadequacy

a) Relevant institution construction is backward: The development practice of equestrian tourism in western developed countries proves that the market of equestrian tourism is inseparable from the rules and regulations of the law[8]. Because of our country equestrian tourism related system construction lag, there exists a lot of problems: there are low barriers to enter into equestrian tourism market, poor services, and no related professional skills standard, equestrian tourism develop rapidly, but the relevant system construction is quite backward. In the process of equestrian tourism development, it is very important to establish the skill standards of professional service personnel and the 
examination and approval system for equestrian and tourism enterprises. Once standards are missing, the market will be confused, and resources development and market for equestrian tourism will be developed better in accordance with relevant regulations. Supervision is a necessary means to maintain the healthy development of the equestrian tourism market.

b) Lacking of equestrian tourism law: The rapid development of equestrian tourism is closely related to China's economic, social and cultural industries, so relevant laws is crucial to the development of equestrian tourism. From the point of the whole tourism market, tourism in China, including equestrian tourism market order, market system, legal system and supervision mechanism is not perfect, many problems appeared in the equestrian tourism market activities mainly because there are no specific laws to solve the problems ; Relevant departments should speed up the pace of perfecting the relevant laws and regulations, using the law to restrain and standardize the equestrian tourism market activities, to protect the legitimate rights and interests of consumers and tourism enterprises, which is the inevitable requirement of equestrian tourism industry development in our country. The current tourism legal system in China is far from suitable for the development of equestrian tourism. The rapid and healthy development of equestrian tourism market urgently needs relevant laws.

4) Lacking of equestrian tourism professionals: Equestrian tourism is a new project combining tourism and equestrianism. Its industrial chain covers a wide range and is closely related to jockeys, coaches, horse breeding, nursing, training, horses, and veterinarians and so on . Equestrian tourism in China has lacking of a professional technology, management talents, and many professional training institutions and the system are not mature in management, the quality of service does not reach the designated position, lower employment threshold, the staff overall quality is not adapt to the requirements of the development of problem, with the continuous development of tourism industry, the importance of professional talent training gradually appear, the lack of equestrian tourism professionals is the main reason for the equestrian tourism development in our country.

\section{COUNTERMEASURES TO PROMOTE THE DEVELOPMENT OF EQUESTRIAN TOURISM IN CHINA}

\section{A. Increasing the Spread of Horse Culture}

1) Development of horse culture: Since ancient times, horses have occupied a very important position in the development of our country's history. The horse culture has been influenced by the classic allusions, such as Tian Ji's horse racing and the old horses know its way, and other classic allusions. China has a splendid horse culture, and the horse culture is profound. However, for the factors of the history, economy and culture, the development of horse culture has been hindered.. Based on the huge crisis in the development of horse culture, we must fully develop and use horse culture, paying attention to the protection of horse culture, absorbing the essence of ancient horse culture in China and combining the requirements of modern development to develop the horse culture with Chinese characteristics, and attaching great importance to horse culture and other industries, especially with tourism development, will maximize the horse cultural resources.

2) Integrating marketing development of equestrian tourism: In order to promote the development of equestrian tourism, it is necessary to formulate a suitable marketing method to integrate the tourist experience with the existing tourism infrastructure and enterprises. And combining with characteristic of equestrian tourism industry using the way of modern media such as we-media for equestrian tourism publicity, at the same time, tourism administrative departments and enterprises should actively increase the propaganda cost, increasing investment in equestrian marketing, increasing the visibility and responsiveness of equestrian tourism, improving the tourism market share.

\section{B. Government Conducting Effective Guidance to Encourage the Development of Equestrian Tourism}

1) Strengthening government guidance: Equestrian tourism is a comprehensive industry. It requires the government to determine the development goals, to formulate relevant industrial policies and to guide its development. Policy guidance plays an important role in the development of equestrian tourism and industrial optimization, and can solve the industrial structure and future development issues [9]. Equestrian tourism is affiliated to sports tourism. The development of equestrian tourism requires the government to coordinate the equestrian and tourism departments, to exert their respective advantages and characteristics, to establish a good cooperation and cooperation mechanism, and to promote the rapid development of equestrian tourism through the guiding role of related policies; At the same time, it is necessary for the government to formulate a special equestrian tourism plan, to increase government support, to increase the loan and subsidies for equestrian tourismrelated companies, enterprises, and individuals, and to incorporate equestrian tourism-related projects into national economic and social development plans. We must do a good job in the orderly integration of national and local government planning, to promote the steady development of equestrian tourism, to advocate the sharing and protection of equestrian tourism resources, and to promote the sustainable development of equestrian tourism.

2) Encourage the development of characteristic equestrian tourism towns: Taking advantage of the unique charm and attraction of equestrian tourism, we should develop equestrian tourism towns. The construction of equestrian towns is the exploration of supply side reform, which is beneficial to the sound development of the 
relationship between the government and the market, and is the innovation of economic development in the new era. The development of foreign equestrian tourism has attached great importance to the construction equestrian tourism town. The government supports the capital of equestrian tourism town, and strengthens the construction of equestrian tourism infrastructure. These measures have speeded up the development of foreign equestrian tourism to a great extent. We should combine the experience of foreign equestrian tourism town development with the development characteristics of Chinese Equestrian tourism, to build a Chinese characteristic horse art tourist town, and to speed up the pace of the construction of equestrian tourist town. For developing equestrian tourism town is a good response to the national policy of developing sports tourism town, which is a great development opportunity for equestrian tourism. At the same time, the construction of special equestrian tourism towns can speed up the development of equestrian tourism, to promote the transformation and upgrading of the equestrian tourism industry and having a good role in promoting the revival of horse culture.

3) Improving the legislative system and establishing a market supervision system: The history of overseas equestrian tourism proves that the soundness of the tourism legal system is of vital importance to the regulation of the market, the legitimate operation of the company, and the fair competition environment of the market [10]. Improving equestrian tourism related laws is an effective protection of consumer rights and the legitimate rights and interests of tourism companies, improving the tourism legal system is the basic premise and guarantee of China's tourism market economy, which is the key issue of equestrian tourism development. For the equestrian tourism market, while improving the tourism legislation system, we must establish a supervision system for the tourism market, organically combining the management of various departments and industries with social supervision, rectifying the order of tourism industry companies, and to create a good environment for the equestrian tourism industry. Only in this way can the healthy and stable development of the equestrian tourism market be guaranteed.

\section{Accelerating Personnel Training}

Paying attention to the training of professionals and training high-quality, highly-educated personnel to form a professional experience system. The lack of professional personnel has become one of the important factors restricting the development of equestrian tourism. Only the comprehensive improvement of the ability of the entire industry's employees can make the development of the entire industry on the right track. Talent cultivation is an inevitable requirement for the sustainable development of the equestrian tourism industry. Establish a professional talent system, so we should innovate talent training methods, support enterprises in cooperation with equestrian colleges and tourism colleges, and jointly train, and promote cooperative education and training between equestrian colleges and tourism institutes. If we are conscious to establish relevant skills training and training certification systems, we will lay the foundation for the sound development of the equestrian industry.

\section{CONCLUSION}

With the improvement of the overall living standards of the society, people pay more attention to experiential consumption, and equestrian tourism activities enter people's eyes with a new lifestyle concept. The strong foundation for the development of equestrian tourism has been established in China since ancient times, for the strong background of the horse culture, the good trend of the development of equestrian sports, the great situation of the development of the whole tourism industry and the guidance of the relevant national policies. Combining the development history of equestrian tourism in developed countries and the current status of equestrian tourism development in China, we will increase the support for the dissemination of Chinese horse culture and the government should encourage the development of equestrian tourism towns, focusing on personnel training, and improving the legislative system to strengthen market supervision. Based on this, the development of equestrian tourism will inevitably create very good economic and social benefits.

\section{REFERENCES}

[1] Zhang Guohong. Chinese Cultural Tourism [M].Tianjin, Nankai University Press, 2001:30-56.

[2] Guo Yafei. Social Sports [M]. Beijing, Beijing Normal University Press, 2012.1.

[3] Zhao Jinling. Analysis of the Characteristics of High-end Sports Tourism Consumption Groups in China [J]. Business Economics Research, 2015, (03): 127-130.

[4] National Tourism Administration 2016 Tourism Statistics [EB/OL] HTTP://www.cnta.gov.cn/xxfb/jdxwnew2/201608.html.

[5] China Equestrian Official Website [EB/OL]. http://equestrian.sport.org.cn/cjfb/ssjh/2017-03-23/518091.html.

[6] State Council Concerning Accelerating the Development of Sports Industry and Promoting Sports Consumption Several opinions Government information disclosure column [EB/OL].

http://www.gov.cn/zhengce/content/2014-10/20/content_9152.htm.

[7] "13th Five-Year Plan" for sports development _ the State Council department's government Affairs network _ China Government Network[EB/OL].http://www.gov.cn/xinwen/201605/05/content_507 0514.htm.

[8] Shui Jianfeng, Huang Huangnai. Analysis of the status quo of Chinese horse culture research $[\mathrm{J}]$. Science and Technology Information, 2010, (22): 409.

[9] Zhao JL. Theory and empirical research on high-end sports tourism in China [D]. Fujian Normal University, 2013.

[10] Wang Shaohua. Theory, Method and Practice of Feasibility Study of Tourism Development [D]. Northwest Normal University, 2001. 